\title{
Daha Hızlı Bölgesel-Evrişimsel Sinir Ağları ile Sığır Yüzlerinin Tanınması
}

\section{Recognition of Cattle Faces Using the Faster R-CNN}

\author{
Emre Dand1 $^{1 *}$, Musa Turkan ${ }^{2}$, Mustafa Boğa ${ }^{3}$, Kerim Kürşat Çevik ${ }^{4}$ \\ Geliş / Received: 15/07/2019 \\ Revize / Revised: 10/08/2019 \\ Kabul / Accepted: 13/08/2019
}

$\ddot{O}$

z- Süt sığırcılığı işletmelerinde sürülerinin yönetilmesinden ziyade ineklerin bireysel olarak refahı ve sağlıklı olmasına yönelik hassasiyet son yıllarda artmıştır. Bu durumun sonucu olarak, bireysel olarak hayvanların takip edilme ihtiyacı ortaya çıkmıştır. Hayvanlar için biyometrik veriler kullanılarak oluşturulacak sistemler, hayvanları bireysel olarak tanınmasına yardımcı olmaktadır. Hayvanlardan elde edilen yüz, burun, iris gibi bireysel biyometrik veriler işlenerek makine öğrenmesi temelli sistemler oluşturulabilir. Bu çalışmada, derin öğrenmede önemli bir model olan Daha Hızı Bölgesel-Evrişimsel Sinir Ağları(DHB-ESA) kullanılarak, sığırların yüz görüntülerinin sınıflandırılarak tanınması gerçekleştirilmiştir. Çalışmada öncelikle, bir besi yerinde bulunan sığırlardan yüz görüntülerini içeren görüntüleri alınarak bir veriseti oluşturulmuştur. Daha sonra, sığır görüntülerindeki yüz bölgeleri, uygulama ile işaretlenerek sığır sınıflarına göre etiketlenmiştir. Deneysel çalışmalar kapsamında, veriseti içerisinden beş farklı sığıra ait toplamda 1579 görüntüden oluşan bir alt küme oluşturulmuştur. Bu küme, ağın eğitimi için 1129 görüntü ve test işlemi için ise 450 görüntü olacak şekilde gruplandırılmıştır. Sığır yüz görüntüleri ön-eğitimli bir ağ üzerinde eğitildikten sonra, gerçekleştirilen test işlemlerinde sığır yüz görüntüleri \%98.44 doğruluk ile başarılı bir şekilde sınıflandırılmıştır. Önerilen bilgisayar destekli bu yaklaşımın, sığırların yüzlerinin tanınmasında ikincil bir araç olarak uzmanlar tarafından farklı amaçlar için kullanılabileceği öngörülmektedir.

Anahtar Kelimeler- Hayvan Biyomerisi, Sığır Yüzü Tanıma, Derin Öğrenme, Daha Hızlı Bölgesel-Evrişimsel Sinir Ağları, Sınıflandırma

\begin{abstract}
A
bstract-Sensitivity to individual welfare and health of cows has increased in recent years rather than managing herds in dairy cattle holdings. As a result of this situation, the need to follow the animals individually emerged. Systems for animals using biometric data help identify animals individually. Machine learning based systems can be created by processing individual biometric data such as face, muzzle, iris from animals. In this study, facial images of cattle are classified and identified using faster regional-convolutional neural networks (faster R-CNN), which is an important model in deep learning. In the study, firstly, a dataset containing face images is obtained from cattle in a fattening site. The facial regions in the cattle images are then labelled by application according to cattle classes. Within the scope of experimental studies, a subset of 1579 images of five different cattle is created from the dataset. This subset is grouped into 1129 images for network training and 450 images for testing. After training on a pre-trained network of cattle face images, cattle face images are successfully classified with $98.44 \%$ accuracy in the performed test procedures. It is envisaged that this proposed computer-aided approach can be used by experts as a secondary tool in recognizing the faces of cattle for different purposes.
\end{abstract}

Keywords- Animal Biometry, Cattle Face Recognition, Deep Learning, Faster Regional-Convolutional Neural Network, Classification

\footnotetext{
*Sorumlu yazar iletișim: emre.dandil@bilecik.edu.tr_ (https://orcid.org/0000-0001-6559-1399)

${ }^{1}$ Bilgisayar Mühendisliği Bölümü, Mühendislik Fakültesi, Bilecik Şeyh Edebali Üniversitesi, Bilecik, Türkiye

2iletişim: musa.turkan@bilecik.edu.tr (https://orcid.org/0000-0002-4370-7474)

${ }^{2}$ Bilgisayar Mühendisliği Anabilim Dall, Fen Bilimleri Enstitüsü, Bilecik Şeyh Edebali Üniversitesi, Bilecik, Türkiye

3iletişim: mboga@ohu.edu.tr (https://orcid.org/0000-0002-2845-4528)

${ }^{3}$ Gıda İşleme Bölümü, Niğde Ömer Halisdemir Üniversitesi, Bor, Niğde, Türkiye

4İletişim: kcevik@akdeniz.edu.tr_https://orcid.org/0000-0002-2921-506X)

${ }^{4}$ İşletme Enformatiği Bölümü, Akdeniz Üniversitesi, Manavgat, Antalya, Türkiye
} 


\section{GİRIŞ}

Dünyadaki sığır popülasyonuna bakıldığında pek çok farklı bölgeye dağılmış olduğu görülmektedir. İnsan nüfusunun yoğun olduğu yerlerde ihtiyaç halinde sığır transferleri de söz konusu olabilmektedir. Devletler her y1l büyük baş hayvan envanteriyle ilgili raporlar hazırlamakta ve çalışmalar yapmaktadır. Vatandaşlarının sağlıklı hayvansal gıda ihtiyaçlarını temin etmek ve yönetebilmek için bu envanter bilgilerine ihtiyaç duyulmaktadır. Bu durum çiftlik sığırları için güçlü ve güvenilir bir kimlik takibinin önemini ortaya koymaktadır[1]. Aksi halde taşıma sırasında kulak numaralarından hayvanların tek tek mühendis tarafından bakılıp raporlanması hem zaman hem de daha fazla personel çalışması olarak karşımıza çıkmaktadır.

Günümüz çiftlik üreticileri için, özellikle sığırların kayıt altına alınması ve sağlıklı şekilde izlenmesi hayvanların sağlığını, güvenliğini ve işletmenin karlılığını da etkileyebilecek konuların başında gelmektedir. Bu şekilde tasarlanan sistemler, hasta hayvanların tanınması ile takibi ve kontrolü sağlamayabilmekte, üreticilerin maddi kayıplarını azaltmakta ve salgın hastalık gibi olağanüstü durumların önüne geçebilmektedir[2].

Hayvanların tanınması için birçok yöntem vardır ve bunlar temel olarak mekanik, elektronik ve biyometrik olmak üzere üç grupta değerlendirilebilir[3]. Mekanik genellikle olanlar damga, kulak küpesi, dövme şeklinde olmak birlikte hayvana acı verebilmektedir[4]. Elektronik temelli olanlar ise RFID (Radio Frequency IDentification) teknolojisi ile bir alıcı ve verici donanım tümdevresi şeklinde kullanılmaktadır [5]. Heme elektronik hem de mekanik yöntemler inekleri tekil kimlik olarak tanılama konusunda bir takım kısıtlara sahiptirler. RFID kartların başka hayvanlara küpe olarak takılabilmesi, çip temelli küpelerin mandıra şartlarında bozulması, küpelerin farklı hayvanlara takılması gibi durumlarda hayvanları takip etmek sağlıklı olmayabilmektedir. Uluslararası hayvan ticaretinde sahtecilik, çalınma gibi durumlarda sensör temelli geleneksel yöntemler sağlıklı bir çözüm sunamamaktadır[1]. Hayvanlarda biyometrik veri kullanılarak kimlik saptama konusundaki çalışmalar son yıllarda artmış ve başarılı sonuçlar elde edilen çalışmalar sunulmuştur. Biyometrik hayvan tanıma sistemleri ise çoğunlukla hayvan burnu, iris ve yüz ile tekil olarak tanımaya elverişli yaklaşımları içermektedir[6-8]. Aynı zamanda son yıllarda hayvan refahı da uluslararası düzeyde ülkelerin önemle üzerinde durduğu bir konu olarak karşımıza çıkmaktadır. Hayvanlara takılacak olan kart sistemlerin hayvanlara her hangi bir şekilde acı çektirmesi de karşımıza olumsuz bir durum olarak çıkmaktadır. Bu gibi sebeplerden dolayı hayvanlarda otomatik kimlik tanıma için makine öğrenmesi yöntemlerine dayalı iskelet yapı geliştirilmesi konusu son zamanlarda üzerinde durulan bir konudur.

Biyometrik veri kullanan sistemlerde sensörlerle veri toplama, desen tespiti, desen eşleştirme, depolama, uygulamalarla etkileşime girme (çıkarılan bilgileri kullanan kullanıcılar) olmak üzere beş ana bileşen bulunur [9]. Pek çok biyometrik tanıma sistemi bu bileşenlerden bir veya birden fazlasını kullanır. Sensörlerle elde edilen veriler özellik çıkarım algoritmalarıyla işlenerek o hayvana özel veriler kayıt edilmektedir. Hayvan biyometrik verisi bir türün anatomisi veya davranışı nedeniyle görüntülenebilen ölçülebilir bilgidir. Tipik olarak hayvanların görünüm özellikleri, davranış özellikleri ve ses özellikleri seçilip biyometrik veri olarak kullanılabilir. Ölçülebilir biyometrik değerleri belirlemek için hayvan görüntülerini seçmek en zor konulardan biridir. İlgilenilen özellikler hayvanın hususiyetlerini belirtmeli, kayıt cihazlarıyla doğru şekilde kayıt edilebilmeli, ölçülebilir olmalıdır. Görsel hayvan biyometrisi, bilgisayarlı görme, örüntü tanıma ve bilişsel bilimlerde ortaya çıkan bir araştırma disiplinidir. Bu alan hayvan davranışlarının analiz edilmesine de yardımcı olur. Hayvanları tekil kimlikle tanıyabilmek için çeşitli biyometrik özellikleri kullanılmaktadır. Derisindeki desenler, burun görüntüleri, sırt desenleri gibi biyometrik özellikler her hayvan için tekildir[10].

Bu çalışmada, hayvanların kimliklendirilmesine katkı sağlamak için yüz-tabanlı bir biyometrik sığır tanıma yaklaşımı önerilmiştir. Sistem üç önemli aşamadan meydana gelmektedir. Birinci aşamada, bir çitlikte bulunan sığırların video ve resimleri kullanılarak bir veriseti oluşturulmuştur. İkinci aşamada ise, sığır görüntülerin sınıflarına göre etiketleme işlemi gerçekleştirilmiştir. Üçüncü ve son aşamadaysa, Daha Hızlı Bölgesel-Evrişimsel Sinir Ağları(DHB-ESA) kullanılarak, bir ön-eğitimli ağ modeli (Faster R-CNN Inception v2 Coco) üzerinde verisetinin eğitim kısmı için ayrılan kümesi ile eğitim işlemi tamamlandıktan sonra, teste kümesi üzerinde sığırların yüz bölgelerinden tanınma işlemi sağlanmıştır. Çalışmanın geri kalan kısmı şu şekilde organize edilmiştir. İkinci bölümde, sığır tanıma ve sınıflandırma sistemleri için bilgi teknolojileri tabanlı ilgili çalışmalar özetlenmiştir. Üçüncü bölüm önerilen yaklaşımda kullanılan materyal ve metotlar ile ilgili açıklamalar sunulmuşken, dördüncü bölümde ise DHB-ESA ile oluşturulan veriseti üzerinde gerçekleştirilen deneysel çalışmalar ile elde edilen sonuçlara değinilmiş ve değerlendirmesi yapılmıştır. Son bölümde ise, çalışma sonucunda ulaşılan buldular ve elde edilen sonuçlar tartışılmıştır. 


\section{LITERATÜR ARAŞTIRMASI VE BENZER ÇALIŞMALAR}

Hayvan ölümlerinin azaltılması veya olmaması için, hayvancılık ile ilgili faaliyetlerde görüntü işleme ile makine öğrenmesi yöntemlerinin kullanımı her geçen gün artarak devam etmektedir. Özellikle hayvanların izlenmesinde, hayvan davranışlarının belirlenmesinde ve mevcut aktivitelerinin-durumlarının yerinde tespiti ve kötü yönetim koşullarının giderilmesi, son zamanlarda araştırmacılar tarafından üzerinde durulan bir konu olarak karşımıza çıkmaktadır [11]. Sadece büyükbaş hayvanların tanınması değil, diğer hayvanların da izlenmesine yönelik kameralar ile desteklenmiş uyarı ve tespit sistemlerinin hayvancılık alanında yaygın olarak tercih edildiği görülmektedir. Bu şekilde önerilmiş çalışmalardan birisinde[12] Şekil 1'de görüldüğü gibi ve kameralar tarafından çekilen görüntüler analiz yazılımı ile etlik piliç kümesinde anormal hayvan davranışı ve azalan büyüme oranı, hastalıklar, beslenme ve içme hatlarında teknik arızalar ve optimal yönetim prosedürleri gibi istenmeyen bir durumu gösterebilen birkaç işaretten yola çıarak, refahın veya piliçlerin üretimine zarar vermekten kaçınmak için sorunların erken bir aşamada tespit edilmesinin önemi üzerinde araştırmalar yapılmıştır. Bu çalışmaya benzer olarak, Shalika ve Seneviratne [13] ise çalışmalarında, hayvan araştırmacıları ve vahşi yaşam fotoğrafçıları için vahşi hayvanları otomatik olarak algılamak ve tanımak için bir sistem kurmuşlardır. Hayvanların tespiti ve tanınmasının yanında, hayvan davranışlarını incelemek için değerli zamanlarını ayıran hayvan araştırmacılarına ve vahşi yaşam fotoğrafçılarına yardımcı olacak bir sistem oluşturmuşlardır. Bu araştırmada kullanılan teknoloji, güvenlik, izleme amaçları gibi uygulamalarda da kullanılabilmektedir. Hayvanların görüntü işleme ve makine öğrenmesi tabanlı yaklaşımlar ile izlenmesine yönelik bir başka çalışmada, Parikh vd. [14] çalışmalarında, şablon eşleme algoritmasını kullanarak hayvan algılama ile bölgede yabani hayvan tespiti, hayvan-araç kazalarının önlenmesinde faydalı ve insan ve vahşi yaşam güvenliğini artırması üzerine çalışmışlardır. Çalışmalarında yaban hayvanlarının yola girmeden önce tespit edilerek, sürücüyü sesli ve görsel sinyallerle uyarı sağlanması ile olası kazaların engellenmesi amaçlanmıştır. Çalışma sayesinde çiftçilerin uyarılarak, çiftlikteki mahsullerin hayvanlardan korunmasına da yardımcı olduğu belirtilmiştir.

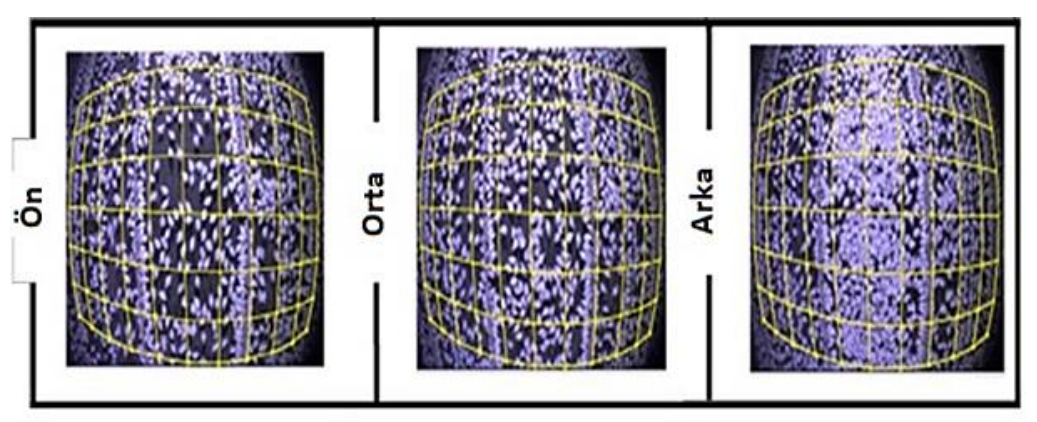

Şekil 1. Bir kameranın görüntüsünde $60 \times 1 \times 1 \mathrm{~m} 2$ alanlara ayrılan eYeNamic ile donatılmış bir piliç evindeki zemin yüzeyinin resmi[12]

Son yıllarda sığır, bizon ve inek gibi hayvanların tekil olarak tanınması, hastalık izleme, aşılama ve ürün yönetimi, hayvanın takibi ve hayvan sahiplerinin belirlenmesi gibi konuların anlamlandırılması için önemli bir rol oynamıştır[15]. Biyometrik olarak sığır tanıma ve izleme bir işaretçi ve kimlik ile sığırın doğru olarak sınıflandırılmasını sağlayan bir dizi prosedürden oluşmaktadır. Konu ile ilgili çalışmalar incelendiğinde, biyometrik tabanlı sığır tanıma için önerilmiş birçok çalışma olduğu görülmektedir[6, 16]. Hayvanlarda biyometrik tanıma işlemlerinde genellikle yüz, burun, desen ve iris gibi tekil öznitelikler içeren özellikler kullanılmaktadır. Yüz tanıma ile yapılan bir biyometrik sığır sınıflandırma çalışmasında Kumar vd. [17] çalışmalarında önerdikleri yöntem ile sığır yüzlerinin aynı olmadığı kanıtlamaya çalışmışlardır. 1200 sığır yüz görüntüsünün olduğu bir veritabanında, sığırların kimlikleri yüz görüntüleri kullanılarak yüksek doğruluk ile tanınmıştır. Çalışmada yüz görüntülerinin sınıflandırılmasında, yerel ikili örüntüler (LBP) ile özellik çıkarma yapılmış SURF (Speer Up Robust Feature) le eşleşme prosedürü yürütülmüştür.

Burun görüntüleri her hayvanda farklı desenler barındırmaktadır[18]. Literatürde hayvan burun görüntüleri ile biyometrik olarak tanıma sağlayan birçok çalışma bulunmaktadır[6, 19, 20]. Bunların birisinde Kumar vd. [21] burun noktası görüntüleri kullanarak, hayvanları kimliklendirmiştir. Çalışmada, kamera ile hayvanların burun görüntüleri elde edilerek RFID etiketleri, çipli küpeler kullanan geleneksel yöntemlere göre daha kolay bir kimliklendirme sağlayabilecek bir yöntem önerilmiştir. Çalışmada, zengin doku farklılıkları bulunan burun resimleri elde edilmiş ve sonra veritabanında bulunan resimlerin doku özellikleri çıkartılmış ve bu özellikler derin öğrenme teknikleri kullanılarak sınıflandırılmıştır. Burun görüntüleri kullanılarak gerçekleştirilen bir diğer çalışmada, Mahmoud vd. [22] çalışmada Destek Vektör Makineleri(SVM) kullanılarak sığır tanıma yapıllmıştır. 
Aynı sığırlar için ortaya çıkan özellik vektörü yaklaşık aynı olmuştur. Gaber vd. [2] 31 büyükbaş havyandan elde edilen burun bölgesi görüntüleri kullanarak sığır tanıma için bir yöntem önermişlerdir. Burun noktasından özellikler çıkarmak için Weber'in yerel tanımlayıcılarını kullanmışlardır. Çalışmada inek başlarını belirmek için AdaBoost sınıflandırıcısı kullanılmıştır.

Sı̆̆ırların kimliklendirilmesi için bedenlerindeki desenleri kullanma, bir diğer biyometrik tanıma yöntemidir. Bu çalışmalardan birisinde Zin vd. [23] inekleri tekil olarak tanıyabilmek için derin öğrenme temelli bir yöntem sunmuşlardır. Çalışmada, elde edilen görüntülerde beden bölgesi tespit edildikten sonra ineklerin bedenlerinde bulunan siyah beyaz desenlere odaklanarak bu desen farklılıklarının kimlik olarak belirlenmesi sağlanmıştır. Buna benzer bir diğer çalışmada Choi vd. [24] Holstein ırkı ineklerin bedenlerindeki desenleri kullanarak kimliklendirme gerçekleştirmişlerdir. Çalışmada 49 farklı ineğin görüntüleri kullanılmış olup, Yapay Sinir Ağları(YSA) ile ineklerin sınıflandırılması gerçekleştirilmiş̧tir.

Sığırların tanınması için insan iris yapısında olduğu gibi, sığırların iris yapılarına göre sınıflandırılmasını öneren bazı biyometrik çalışmalar da bulunmaktadır. Bu şekilde geliştirilen yaklaşımların birisinde Sun vd. [25] sığırların kimliklendirilmesi için SIFT(Scale-Invariant Feature Transform) yöntemine dayalı bir çalışma gerçekleştirmişledir. Yine benzer olarak Lu vd. [26] 2B dalgacık dönüşümü yapıllmış iris görüntülerini kullanarak inek kimliklendirme sistemi önermişlerdir.

Bu çalışmada ise, sığırların kimliklendirilmesi için, bir derin öğrenme modeli olan DHB-ESA kullanarak yüz-temelli bir biyometrik tanıma yaklaşımı önerilmiştir. Görece az verinin olduğu durumlarda ağın başarımını düşürmeden, daha kısa sürede ağı eğitmek için önceden eğitilmiş bir modeller kullanılmıştır. Çalışmada 31652 adım eğitim aşaması sonunda beş farklı sınıfa ait sığırların doğru şekilde sınıflandırılması yüksek başarım ile gerçekleştirilmiştir.

\section{MATERYAL VE YÖNTEM}

$\mathrm{Bu}$ çalışmada sığır görüntülerini sınıflandırmak için, öncelikle sığır görüntülerinden bir veriseti oluşturulmuştur. Versetindeki görüntülerin bir kısmı ön-eğitimli ağ üzerinde eğitim aşaması için kullanılırken bir kısmı ise test süreci kullanılmıştır. Verisetindeki görüntüler sınıflarına göre etiketlendikten sonra, tanıma işleminin gerçekleştirilmesi için Google tarafından geliştirilen bir kütüphane olan Tensorflow içerisindeki DHB-ESA kullanılmıştır. Tensorflow kütüphanesi karmaşık sinir ağı mimarilerinin kolaylıkla oluşturulabilmesine imkan vermektedir. Yeni model oluşturulurken Microsoft COCO veri seti ile eğitilmiş faster_rcnn_inception_v2_coco [27] modeli kullanılmıştır. Test işlemleri yeni oluşturulan bu nesne tanıma modeli üzerinde test resimleri uygulanarak gerçekleştirilmiştir.

\section{A. Veriseti Oluşturma}

Çalışma süresince farklı zaman dilimlerinde, kamera yardımı ile bir çiftlikte bulunan beş farklı inek üzerinde görüntü kayıt işlemleri yapılmıştır. Görüntü alınan sığırlar sağlıklı kilolarında ve yaklaşık 4 yaşlarındadırlar. Sığır yüz veriseti oluşturmak için toplanan görüntüler 4K-14.2 MP Sony Video Kamera kullanılarak elde edilmiştir. Teknik ekipman temin edildikten sonra sığırlar belirli süre izlenmiştir ve görüntü almak için uygun fiziki ortam oluştuğunda sığırların yüzü görünecek şekilde farklı açılardan görüntüler elde edilmiştir.

Verisetinde beş farklı ineğe ait çoğunlukla farklı açılardan yüz bölgelerinin hakim olduğu toplamda 1579 tane görüntü toplanmıştır. Bu görüntülerden 200 tanesi Sığır 1, 172 tanesi Sığır 2, 384 tanesi Sığır 3, 467 tanesi Sığır 4 ve 356 tanesi ise Sığır 5'e aittir. Görüntüler uygun bir mesafeden ineğin yüzü görünecek şekilde hem resim, hem de video şeklinde kaydedilmiştir. Verisetine eklenen bazı görüntüler video çerçevelerinden elde edilmiştir. Tüm veriseti ağ üzerindeki deneysel çalışmaların yürütülmesi için eğitim kümesi ve test kümesi olmak üzere iki alt kümeye ayrılmıştır. Verisetindeki görüntülerin 1129 tanesi (Sı̆̆ır 1=103, Sığır 2=91, Sığır 3=312, Sığır 4=359, Sığır 5=264) eğitim kümesi olarak, 450 tanesi (Sığır 1=97, Sığır 2=81, Sığır 3=72, Sığır 4=108, Sığır 5=92) ise test kümesi olarak gruplandırılmıştır. Şekil 2'de görüntü verisetinde bulunan Sığır 1, Sığır 2, Sığır 3, Sığır 4 ve Sığır 5 inek türlerine ait yüz görüntülerinin ağırlıklı olduğu bölgelerden alınmış bazı örnek görüntüler sunulmuştur. Verisetinde aynı zamanda sığırların yüz bölgelerinin tam olarak görünmediği örüntüler de bulunmaktadır. Test işlemlerinde önerilen yaklaşımın bu şekildeki görüntülerin doğru olarak tanınmasının başarımı da ölçülmüştür. 


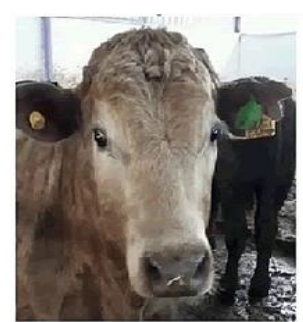

Sığır 1

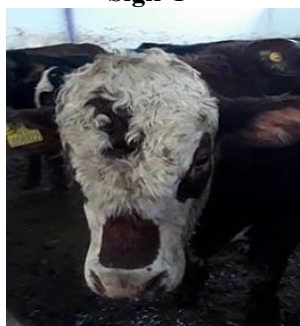

Sığır 3

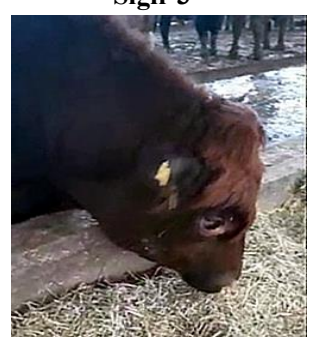

Sığır 4

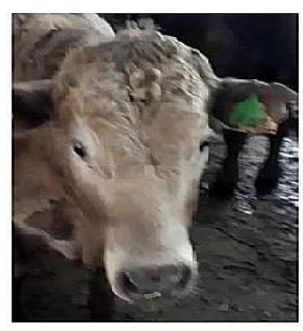

Sığır 1

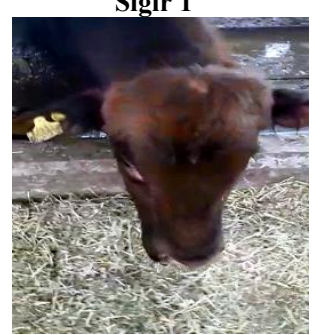

Sığır 4

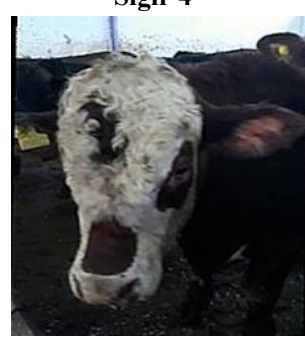

Sığır 3

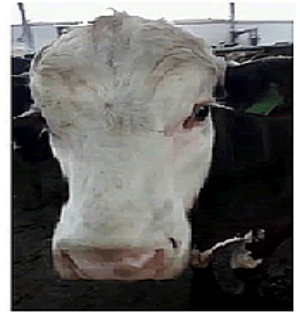

Sığır 2

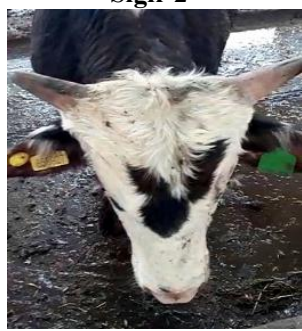

Sığır 5

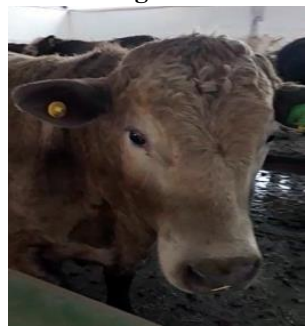

Sığır 1

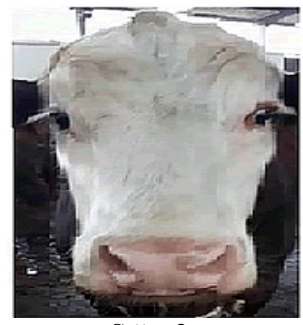

Sığır 2

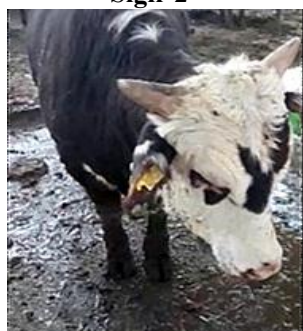

Sığır 5

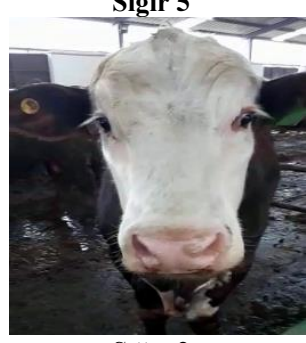

Sı̆̆ır 2

Şekil 2. Görüntü verisetinde bulunan beş farklı sığıra ait resimler

\section{B. Evrişimsel Sinir A Ălarl}

Derin öğrenme, çok büyük sayıda veriden özelliklerin çıkarılması aşamasında kullanılan ve çok katmanlı yapıya sahip olup makine öğrenmesinin bir alt grubu olarak incelenmektedir. Derin öğrenme için kullanılan modellerin en popüler olanlarından biri Evrişimsel Sinir Ağları (ESA)'dır. ESA bilgisayarlı görü uygulamalarında kullanılmak üzere geliştirişmiş çok katmanlı yapay sinir ağlarının özel bir modelidir. Biyolojik süreçlerden esinlenilmiş, özellik çıkarma ve sınıflandırmayı birleştirerek, doğrudan görüntünün piksellerinden (veya diğer sinyallerden) kalıpları tanımak üzere tasarlanmış ileri beslemeli yapay sinir ağlarıdır[28].

Derin öğrenme çatısı içerisinde birçok sınıflandırma modeli bulunmaktadır ve birçok alanda kullanılmaktadır. Görüntü tanıma ve sınıflandırma ile ilgili olarak yapılan uygulamalarda ESA, en güçlü sınıflandırma modeli olarak karşımıza çıkmaktadır [29]. Altyapısında evrişim/konvolüsyon (convolution) katmanı, havuzlama (pooling) katmanı, aktivasyon(ReLu) katmanı, tam bağl katman (fully connected layer) ve yumuşatma (softmax) gibi kendine özgü görevleri olan ayrı katmanları barındırır. Şekil 3'te genel mimarisi gösterilen ESA genel olarak giriş, konvolüsyon katmanı, havuzlama katmanı, tam bağlantı katmanları ve sınıf kararından oluşmaktadır. Bir ESA, bir veya daha fazla evrişim katmanından oluşur ve bu katmanları takip eden çok katmanlı bağlı bir standart sinir ağından oluşur. Evrişim katmanları sonunda genellikle havuzlama işlemi yapılarak parametre sayısı azaltılır. CNN ağları standart sinir ağlarına göre daha kolay eğitilebilirler ve daha az parametreye sahiptirler. ESA ile görüntüler işlenirken, görüntüyü oluşturan pikseller düzleştirilerek vektör olarak ağ girişine uygulanır. Görüntüdeki piksel sayısı ve kanal sayısına göre vektörün boyutu değişebilir. Oluşan vektör ağa uygulanarak sınıflandırma yapılır. Görüntü düzleştirildiğinde köşeler, renkli hatlar, oval kısımlar kaybolur. Görüntü üzerinde nesne tanıma için önemli olan bu ince ayrıntıların kaybolmaması için ESA kullanılması daha uygun olacaktır[30]. 


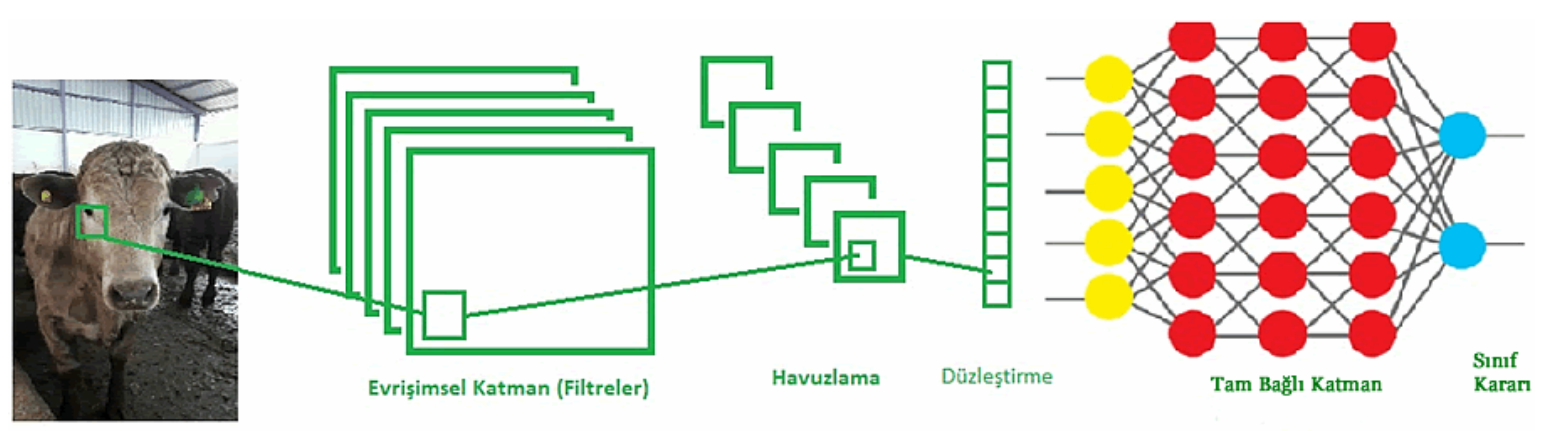

Şekil 3. Evrişimsel Sinir Ağı genel mimarisi

ESA'da, görüntü üzerinde düzleştirme yapmak yerine, filtreler kullanarak görüntünün farklı özellikleri ortaya çıkarılır. Her bir filtre görüntüye ait farklı özelliklerin temsil edilmesini sağlar. Konvolüsyon işlemi sonrasında değerler aktivasyon fonksiyonundan geçirilir. Filtrelerden sonra havuzlama işlemi uygulanır. Havuzlama işlemi sonrasında oluşan katmanlı yapı, düzleştirilerek bir sinir ağına uygulanır. Sınıflandırma işlemi bu ağı yapılır. Böylece görüntüdeki detay özellikler kaybedilmeden sinir ağına uygulanmış olur. ESA'da evrişim katmanı özellikler belirlemek için kullanılırken, aktivasyon katmanı sistemde doğrusal olmayan değerlerin de işlenebilmesini sağlayarak sadece aktif özellikleri bir sonraki katmana taşır. Havuzlama katmanında ağın parametre sayısı azaltılarak işlemlerin hızlandırılması sağlanır. Tam bağlı katman bir sinir ağı olup, bu katmanda sınıf sayısına göre karar işlemleri yürütülür.

\section{Daha Hızlı Bölgesel-Evrişimsel Sinir Ağları (DHB-ESA)}

Bir ESA genel olarak olarak görüntü sınıflandırması için kullanılırken, eğer nesne tanıma yapılacaksa Bölgesel-ESA(B-ESA) tercih edilmektedir[31, 32]. Nesnenin görüntünün neresinde olduğu ve kapladığı sınırların tespiti ise nesne tanımlama işlemidir. B-ESA giriş görüntüsün yanında ilgilenilen bölgenin(ROI) de giriş olarak verildiği bir yapı olarak, daha özelleştirilmiş ESA özellikli bölgeler şeklinde değerlendirilebilir. Bu çalışmadaki gibi sığır yüzlerinin tanınması için tüm görüntüye değil sadece sığırların yüzlerinin olduğu bölgelere odaklanılmaktadır. Tam da burada sistemin daha etkili ve hızlı çalışmasını sağlayan B-ESA devreye girmektedir. DHB-ESA, BESA'dan geliştirilmiş bir ESA tipidir[33]. DHB-ESA ile belirlenen aday bölgelerden rastgele seçim yapılarak sınıflandırma işlemi gerçekleştirilir. DH B-ESA, ESA ile ortaya çıkan aynı sonuçların elde edilmesi problemini ortadan kaldırdığı için hesaplama süresini azaltmaktadır. Bu durumdan dolayı, DHB-ESA gerçek zamanlı tanıma işlemlerinde sıklıkla tercih edilmektedir. Şekil 4'te ESA, B-ESA ve DHB-ESA'nın çalışma süreleri bakımından kıyaslamaları gösterilmiştir.

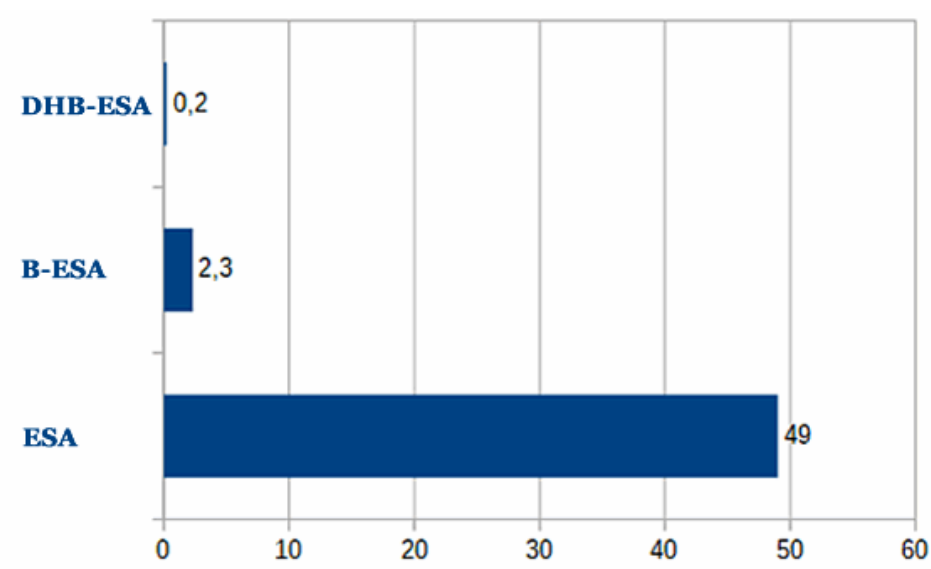

Şekil 4. ESA, B-ESA ve DHB-ESA modellerinin hız bakımından karşılaştırmaları [34]

DHB-ESA modelinde görüntü üzerinde bölge önerisi yapmak yerine resim önce bir ESA katmanından geçirilir ve bir özellik haritası elde edilir. Bölge önerileri ise bu özellik haritası üzerinde yapılır. Böylece belirlenen her bölgeyi ayrı ayrı ESA katmanından geçirmek yerine, görüntü bir kez ESA ağından geçirilmektedir. ESA ağı en 
çok işlem yükünün olduğu katmandır. Bu sayede işlem yükü oldukça düşürülür. DHB-ESA modelinde özellik haritası üzerinde önerilen bölgeler tam bağlı katmanına bağlıdır. Tam bağlı katman belirli bir boyutta giriş beklediği için tespit edilen bölgelerin boyutları bu katmanın girişine uygun hale getirilecek şekilde ayarlanır [32]. Şekil 5'te bu çalışmada da kullanılan DHB-ESA modelinin genel mimarisi sunulmuştur.
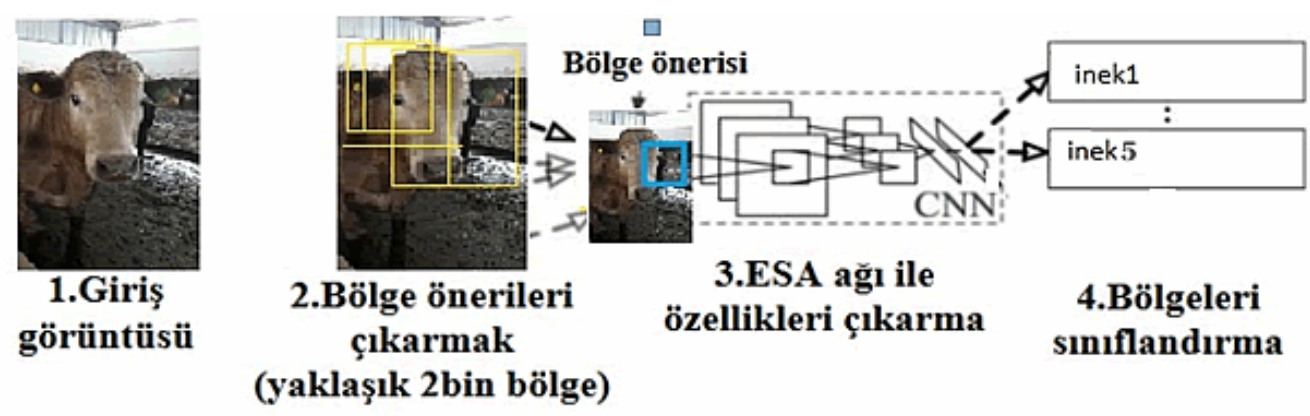

Şekil 5. DHB-ESA modelinin genel mimari yapısı

\section{IV.DENEYSEL ÇALIŞMALAR}

Bu çalışmada oluşturulan bir veriseti üzerinde sığırların yüz görüntülerinden tanınması gerçekleştirilmiştir. Önerilen ESA ağında eğitim algoritması, Momentum (SGDM) değeri 0.001'lik bir başlangıç öğrenme oranı ile Olasılıksal Dereceli Azalma kullanmaktadır. Eğitim aşaması sırasında, ilk öğrenme oranı her 8 adımda bir azaltılmıştır. Olasılıksal dereceli azalma, verimlilik ve kod ayarlama için birçok kolaylık sunmaktadır. Çalışmada yapılan tüm uygulamalar MATLAB yazılımı ile oluşturulan uygulama üzerinde gerçekleştirilmiştir. Tüm deneysel çalışmalar Tablo 1'de özellikleri verilen bir bilgisayar kullanılarak yapılmıştır.

Tablo 1. Deneysel çalışmalar için kullanılan bilgisayarın konfigürasyon bilgileri

\begin{tabular}{ll}
\hline Donanım & Özellik \\
\hline Merkezi İşlemci(CPU) & Intel Core i7-7700K @ 2.8 Ghz (8 CPUs) \\
Bellek(RAM) & 16 GB (DDR4 2400 Mhz) \\
Anakart & ASUS X580VD \\
GPU & NVIDIA GeForce GTX 1050 (4 GB) \\
Harddisk & 256 GB SSD HDD \\
\hline
\end{tabular}

Veriseti için 5 farklı ineğe ait çoğunlukla farklı açılardan yüz bölgelerinin hakim olduğu toplamda 1579 tane görüntü toplanmıştır. Bu görüntülerden 200 tanesi Sığır 1, 172 tanesi Sığır 2, 384 tanesi Sığır 3, 467 tanesi Sığır 4 ve 356 tanesi ise Sığır 5'e aittir. Görüntüler uygun bir mesafeden ineğin yüzü görünecek şekilde hem resim, hem de video şeklinde kaydedilmiştir. Verisetindeki görüntülerin 1129 tanesi (Sığır 1=103, Sığır 2=91, Sığır 3=312, Sığır 4=359, Sığır 5=264) eğitim kümesi olarak, 450 tanesi (Sığır 1=97, Siğır 2=81, Sığır 3=72, Sığır 4=108, Sığır 5=92) ise test kümesi olarak gruplandırılmıştır. Görüntü verisetinde bulunan Sı̆̆ır 1, Sığır 2, Siğır 3, Sığır 4 ve Sığır 5 inek türlerine ait yüz görüntüler ağırlıklı olduğu bölgelerden alınmıştır. Verisetinde aynı zamanda sığırların yüz bölgelerinin tam olarak görünmediği örüntüler de bulunmaktadır.

\section{Siğır Yüzlerinin Etiketlenmesi}

Eğitim verileri içerisindeki sığır görüntülerinde yüzleri etiketlemek için Şekil 6'da gösterildiği gibi LabelImg [35] uygulaması kullanılmıştır. Açık kaynak ve ücretsiz olan bu yazılım ile eğitim setindeki görüntülerde bulunan inekler beş farklı sığır sınıfı olarak İnek 1, İnek 2, İnek 3, İnek 4 ve İnek 5 şeklinde etiketlenmiştir. Bu etiketleme ile görüntüler Tensorflow kütüphanesinin işleme formatına (tfrecord) dönüştürülmüştür. Burada tanıması yapılacak olan nesne bölgesi belirlenmekte ve bu koordinat bilgilerine göre eğitim aşaması yürütülmektedir. 


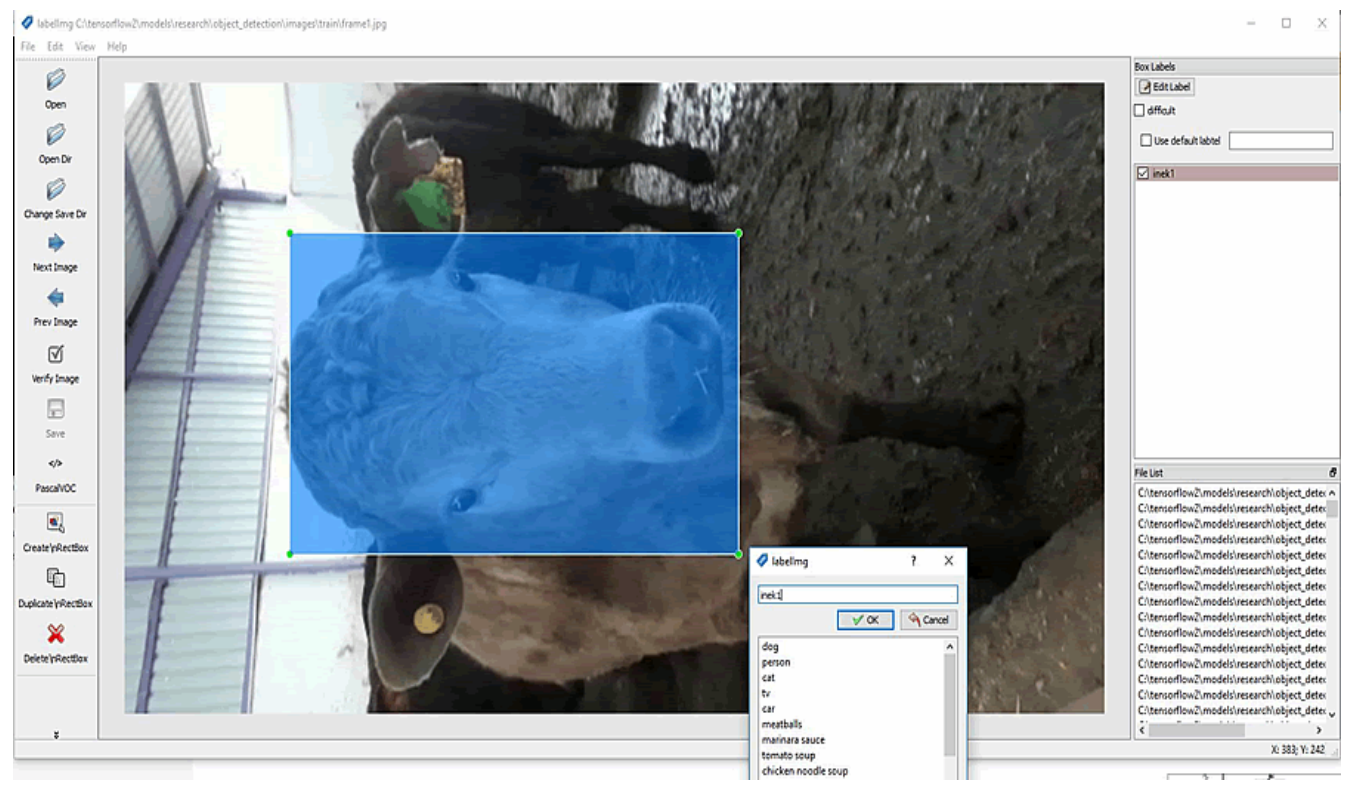

Şekil 6. LabelImage[35] yazılımında sığır yüzlerinin etiketlenmesi

\section{E. DHB-ESA Ĕ̈itimi}

$\mathrm{Bu}$ aşamada etiketlenen bölgelerin koordinatları alındıktan sonra bu koordinatlar önerilen DHB-ESA modeli ile eğitilmektedir. Ağının eğitiminin doğru yapılıp yapılmadığını kontrol etmek için bazı aşamaların takip edilmesi gerekmektedir. Bu aşamalardan birincisi, tanıma işleminin gerçekleştirileceği yüz bölgesinin bulunmasidir.

Verisetindeki görüntüler sınıflarına göre etiketlendikten sonra, sığırların yüzlerine göre tanıma işleminin gerçekleştirilmesi için Google tarafından geliştirilen bir kütüphane olan Tensorflow içerisinde buluna DHB-ESA modeli kullanılmıştır. Eğitim kümesindeki veriler ön-eğitilmiş bir ağ olan Microsoft COCO veriseti ile eğitilmiş faster_rcnn_inception_v2_coco[27] modeli kullanılmıştır. Eğitim aşamas1 31652 iterasyon (devir) ile eğitim yaklaşık 34 saat sürmüştür. Ön-eğitilmiş bir model kullanıldığı için az sayıda eğitim adımı olmasına rağmen model beş farklı sığır sınıfını ayırt başarılı bir şekilde sınıflandırmıştır. Eğitim aşamasında oluşan kayıp (loss) fonksiyonu değerinin zamanla değişim grafiği Şekil 7' de görülmektedir.

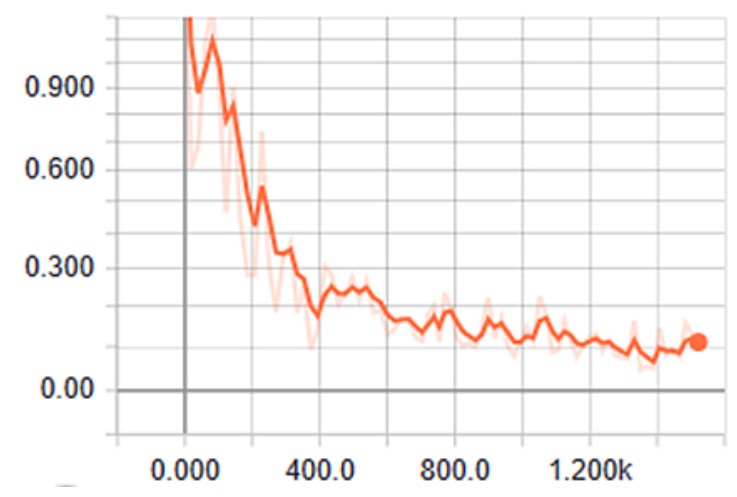

Şekil 7. Eğitim süresince kayıp fonksiyonu grafiği

\section{F. Deneysel Sonuçlar}

Ön-eğitimli ağ üzerinde eğitim tamamlandıktan sonra oluşturulan model kullanılarak test kümesindeki görüntüler üzerinde deneysel çalışmalar gerçekleştirilmiştir. Şekil 8'de test kümesinde bulunan bazı görüntülerde bulunan sığırların DHB-ESA ile tanıma sonuçları gösterilmiştir. Buradan da görülebileceği gibi önerilen yaklaşımın sığırların yüz bölgelerinin kullanılarak tanınmasında başarılı olduğunu göstermektedir. Şekil 9'da 
görüldüğü gibi sığır yüzlerinin dikey olarak bir kısmının göründüğü durumlarda tahmin oranı \%80'lere düşse de model doğru şekilde sınıflandırma yapmıştır. Burun kısımlarının olmadığı yarım görüntülerde ise yanlış bir tahminleme yapılmıştır. İkinci ineğe ait görüntüde sığır yüzünün yarım olduğu bir görüntü eğitimde kullanıldığı için, burun kısmı görünmeyen ineği hatalı olarak inek2 sınıfına atanmıştır.
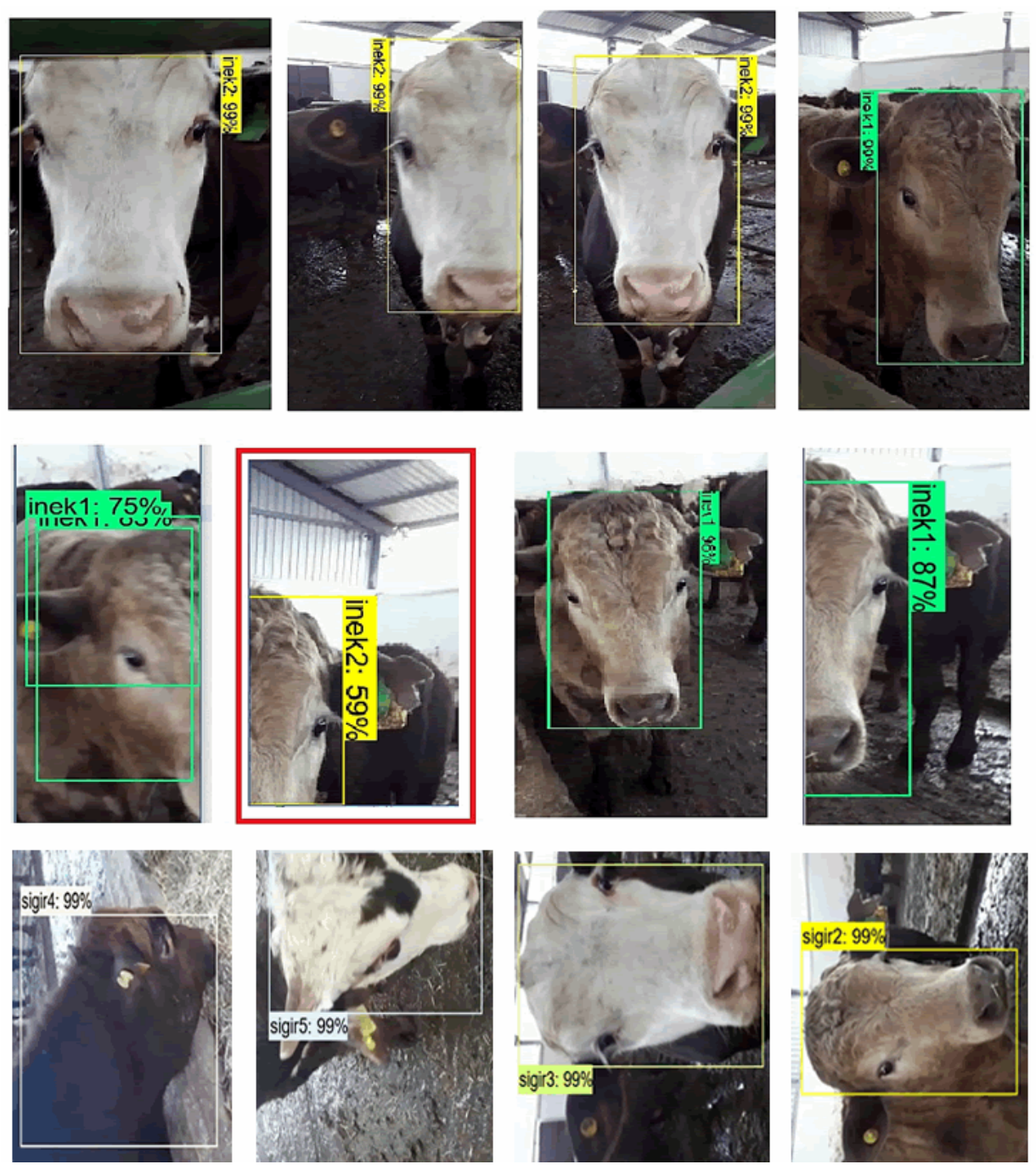

Şekil 8. Başarılı şekilde tanınan farklı sınıflara ait sığır yüz görüntüleri 

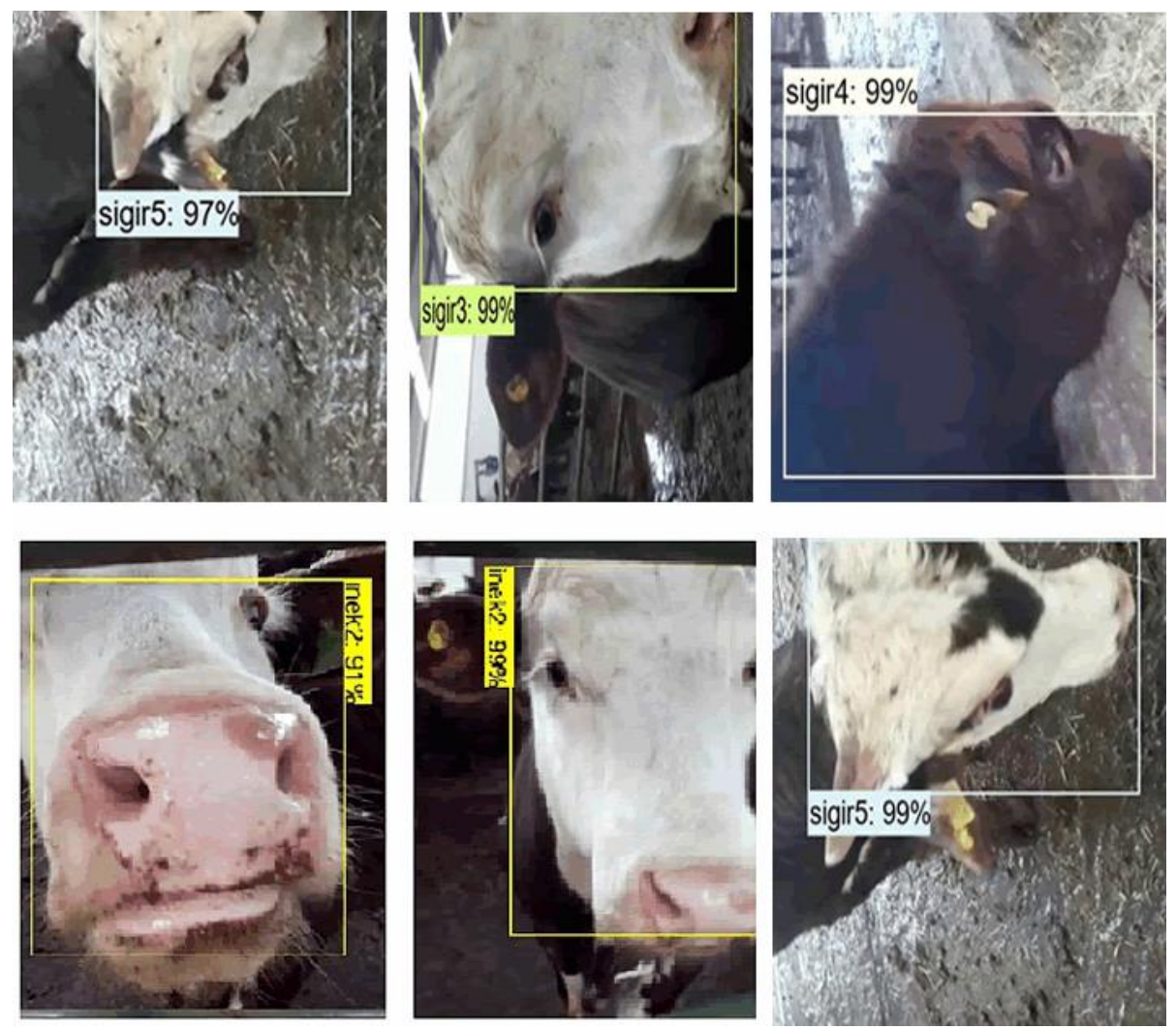

Şekil 9. Sığır yüzünün tam olarak görünmediği görüntülerde yapılmış tahminler

Tablo 2'de deneysel çalışmalar için elde edilen karmaşıklık matrisi gösterilmiştir. Buradan görülebileceği gibi, Sığır 1 sınıfında olan 2 tane sığırın yüz görüntüsü yanlış olarak Sığır 4 olarak, aynı şekilde Sığır 2 sınıfında olan 1 sığırın yüz görüntüsü ise Sığır 3 olarak tanınmıştır. Sığır 3 ve Sığır 4 sınıflarındaki tüm sığırlar doğru bir şekilde tahmin edilmiştir. Bunun yanında, Sığır 5 sınıfındaki 4 tane sığır yanlış tahmin yapılarak Sığır 3 sınıfına eklenmiştir. Toplamda ise test kümesindeki toplam besş farklı sınıfa ait 450 sığır yüz görüntüsünden 443 tanesi başarılı sınıflandırılarak, Sığır 1, Sığır 2, Sığır 3, Sığır 4 ve Sığır 5 olarak gruplanan sığır yüzlerinin ayrımı yüksek bir başarım ile sınıflandırılmıştır.

Tablo 2. Beş farklı sığır sınıfı üzerinde tahmin sonuçlarına ait doğruluk matrisi

\begin{tabular}{|c|c|c|c|c|c|c|c|}
\hline \multirow{2}{*}{\multicolumn{2}{|c|}{ Doğruluk Matrisi }} & \multicolumn{5}{|c|}{ T A H M I N } & \multirow{2}{*}{ Toplam } \\
\hline & & \multirow{2}{*}{$\begin{array}{l}\text { Sığır1 } \\
95 \text { (A) }\end{array}$} & \multirow{2}{*}{$\begin{array}{c}\text { Sığır2 } \\
0\end{array}$} & \multirow{2}{*}{$\begin{array}{c}\text { Sığır3 } \\
0\end{array}$} & \multirow{2}{*}{$\begin{array}{c}\text { Sığır4 } \\
2\end{array}$} & \multirow{2}{*}{$\begin{array}{c}\text { Sığır5 } \\
0\end{array}$} & \\
\hline & Sığır1 & & & & & & 97 \\
\hline$צ$ & Sığır2 & 0 & 80 (B) & 1 & 0 & 0 & 81 \\
\hline $\begin{array}{l}u \\
\propto\end{array}$ & Sığır3 & 0 & 0 & $72(\mathrm{C})$ & 0 & 0 & 72 \\
\hline \multirow[t]{3}{*}{ U } & Sığır4 & 0 & 0 & 0 & 108 (D) & 0 & 108 \\
\hline & Sığır5 & 0 & 0 & 4 & 0 & $88(E)$ & 92 \\
\hline & Toplam & 95 & 80 & 77 & 110 & 88 & $450(F)$ \\
\hline
\end{tabular}


Ayrıca test işlemlerinin başarımını ölçmek için doğruluk parametrik ölçüm kriteri (accuracy, DOG), kullanılmıştır. DOG parametresinin doğru pozitif, doğru negatif, yanlış negatif ve yanlış pozitif değerlerine bağlı olarak hesaplanması Eşitlik (1)'de gösterilmiştir.

$$
\mathrm{DOG}: \frac{\mathrm{DP}+\mathrm{DN}}{\mathrm{DP}+\mathrm{DN}+\mathrm{YN}+\mathrm{YP}}=\frac{A+B+C+D+E}{F}
$$

Tablo 3'te ağ başarım metrikleri için elde edilen DOG sonucu sunulmuştur. Test veriseti üzerinde gerçekleştirilen deneysel çalışmalar neticesinde, Tablo 2'de elde edilen DP, FN, YN ve YP değerlerine göre Doğruluk $(\mathrm{DOG})=\% 98.44$ sınıflandırma doğruluğu başarım sonucuna ulaşılmıştır.

Tablo 3. Sınıf bazında ağ başarım metriklerinin ölçümü

\begin{tabular}{ll}
\hline Başarım Kriteri & Oran $(\%)$ \\
\hline Doğruluk (DOG) & 98.44 \\
\hline
\end{tabular}

\section{SONUÇLAR}

Bu çalışmada, sığırların yüz görüntülerine göre kimliklendirilmesi için derin öğrenmenin DHB-ESA modeline göre bir yaklaşım önerilmiştir. Test veriseti üzerinde gerçekleştirilen deneysel çalışmalar sonucunda, \%98.44 oranında doğruluk ile sınıflandırma başarım sonucuna ulaşılmıştır. Sistemde sığır yüzlerinin dikey olarak bir kısmının göründüğü durumlarda tahmin oranı \%80'lere düşse de model doğru şekilde sınıflandırma yaptığı tespit edilmiştir. Böylece, önerilen bilgisayar destekli bu yaklaşımın, sığırların yüzlerinin tanınmasında ikincil bir araç olarak uzmanlar tarafından farklı amaçlar için kullanılabileceği öngörülmektedir. Sonuç olarak, uygun derin öğrenme modellerinin, çiftlik sığırlarının biyometrik özelliklerinin tanınması, sığırların içinde bulunduğu kötü bakım ve besleme koşullarının daha kısa zamanda belirlenmesi amacıyla kullanılabileceği gösterilmiştir.

Derin öğrenme kütüphaneleri kullanılarak oluşturulan model ile sı̆̆ırlar kolaylıkla sınıflandırılabilmesinin yanında, yeterli sayıda görüntüye sahip bir veriseti olması durumunda sığırların duygularının tanınması da sağlanabilir. Bu durum hayvanların içinde bulunduğu stres ortamının daha kısa zamanda belirlenmesini sağlayabilecektir. Bu amaçla sığır görüntülerinden hayvanların içinde bulunduğu refah durumlarını tanıma amacıyla bir veritabanı oluşturulup derin öğrenme ağlarına uygulanabilir. Ayrıca, derin öğrenme modelleri farklı evcil hayvanların biyometrik özelliklerini tanımak amacıyla da kullanılabilir. Daha hızlı çalışan bir model elde edilmek istenirse daha performanslı çalışan modeller eğitilebilir.

Bu çalışmada kullanılan yöntemde kimlik tanıma modeline yeni sığırlar ilave edilmesi modelin yeniden eğitimini gerektirdiğinden zaman alıcı bir işlemdir. Bundan sonraki çalışmalarda bu eksikliğin giderilmesi sağlanacaktır.

\section{KAYNAKLAR}

[1] Kumar, S., Singh, S. K., Singh, A. K., Tiwari, S., \& Singh, R. S. (2018). Privacy preserving security using biometrics in cloud computing. Multimedia Tools and Applications, 77, pp. 11017-11039.

[2] Gaber, T., Tharwat, A., Hassanien, A. E., \& Snasel, V. (2016). Biometric cattle identification approach based on weber's local descriptor and adaboost classifier. Computers and Electronics in Agriculture, 122, 55-66.

[3] Marchant, J. (2002). Secure animal identification and source verification. JM Communications, UK, 1-28.

[4] Allen, A., Golden, B., Taylor, M., Patterson, D., Henriksen, D., \& Skuce, R (2008). Evaluation of retinal imaging technology for the biometric identification of bovine animals in Northern Ireland. Livestock science, $116,42-52$.

[5] Shanahan, C., Kernan, B., Ayalew, G., McDonnell, K., Butler, F., \& Ward, S. (2009). A framework for beef traceability from farm to slaughter using global standards: an Irish perspective. Computers and electronics in agriculture, 66, 62-69. 
[6] Noviyanto A., \& Arymurthy, A. M. (2013). Beef cattle identification based on muzzle pattern using a matching refinement technique in the SIFT method. Computers and Electronics in Agriculture, 99, 77-84.

[7] Rojas-Olivares, M., Caja, G., Carné, S., Salama, A., Adell, N., \& Puig, P. (2011). Retinal image recognition for verifying the identity of fattening and replacement lambs. Journal of animal science, 89, 2603-2613.

[8] Barry, B., Corkery, G., Gonzales-Barron, U., Mc Donnell, K., Butler, F., \& S. Ward, (2008). A longitudinal study of the effect of time on the matching performance of a retinal recognition system for lambs. Computers and electronics in agriculture, 64, 202-211.

[9] Kühl H. S., \& T. Burghardt, (2013). Animal biometrics: quantifying and detecting phenotypic appearance. Trends in ecology \& evolution, 28, 432-441.

[10] Kumar S., \& Singh, S. K. (2016). Visual animal biometrics: survey. IET Biometrics, 6, 139-156.

[11] Boğa M., Burğut, A. (2018). Görüntü İşleme Yöntemi Kullanılarak Kümes Hayvanlarında Davranışlarının Tahmini, International Congress on Domastic Animal Breeding Genetics and Husbandary (ICABGEH2018), Antalya.

[12] Kashiha, M. A., Bahr, C., Vranken, E., Hong, S., \& Berckmans, D. (2017). Monitoring system to detect problems in broiler houses based on image processing. Int. Conf. Agric. Eng, 2014, pp. 6-10.

[13] Shalika A. U., \& Seneviratne, L. (2016). Animal Classification System Based on Image Processing \& Support Vector Machine. Journal of Computer and Communications, 4, 12.

[14] Parikh, M., Patel, M., \& Bhatt, D., Animal detection using template matching algorithm. International Journal of Research in Modern Engineering and Emerging Technology, 1, 26-32.

[15] Awad, A. I. (2016). From classical methods to animal biometrics: A review on cattle identification and tracking. Computers and Electronics in Agriculture, 123, 423-435.

[16] Awad, A. I., Zawbaa, H. M., Mahmoud, H. A., Nabi, E. H. H. A., Fayed, R. H., \& A. E. Hassanien, (2013). A robust cattle identification scheme using muzzle print images. Federated Conference on Computer Science and Information Systems, 2013, 529-534.

[17] Kumar, S., Tiwari, S., \& Singh, S. K. (2015). Face recognition for cattle. Third International Conference on Image Information Processing (ICIIP), 2015, 65-72.

[18] Barron, U. G., Corkery, G., Barry, B., Butler, F., McDonnell, K., \& Ward, S., (2008). Assessment of retinal recognition technology as a biometric method for sheep identification. Computers and electronics in agriculture, 60, 156-166.

[19] Minagawa, H., Fujimura, T., Ichiyanagi, M., Tanaka, K., \& Fangquan, M., (2002). Identification of beef cattle by analyzing images of their muzzle patterns lifted on paper. Publications of the Japanese Society of Agricultural Informatics, 8, 596-600.

[20] Tharwat, A., Gaber, T., Hassanien, A. E., Hassanien, H. A., \& Tolba, M. F., (2014). Cattle identification using muzzle print images based on texture features approach. Fifth International Conference on Innovations in Bio-Inspired Computing and Applications IBICA 2014, 217-227.

[21] Kumar, S., Pandey, A., Satwik, K. S. R., Kumar, S., Singh, S. K., Singh, A. K., et al., (2018). Deep learning framework for recognition of cattle using muzzle point image pattern. Measurement, 116, 1-17.

[22] Mahmoud, H. A., \& Hadad, H. M. R. E., (2015). Automatic cattle muzzle print classification system using multiclass support vector machine. International Journal of Image Mining, 1, 126-140.

[23] Zin, T. T., Phyo, C. N., Tin, P., Hama, H., \& Kobayashi, I., (2018). Image technology based cow identification system using deep learning. International MultiConference of Engineers and Computer Scientists. 
[24] Kim, H. T., Choi, H. L., Lee, D. W., \& Yoon, Y. C., (2005). Recognition of individual Holstein cattle by imaging body patterns. Asian-australasian journal of animal sciences, 18, 1194-1198.

[25] Sun, S., Yang, S., \& Zhao, L., (2013). Noncooperative bovine iris recognition via SIFT. Neurocomputing, $120,310-317$.

[26] Lu, Y., He, X., Wen, Y., \& Wang, P. S. (2014). A new cow identification system based on iris analysis and recognition. International Journal of Biometrics, 6, 18-32.

[27] Faster R-CNN Inception V2 Coco. Faster RCNN Inception V2 Coco, (2019) https://github.com/tensorflow/models/blob/master/research/object_detection/g3doc/detection_model_zoo.m d, (13.07.2019).

[28] Andrew, N, (2018). Unsupervised Feature Learning and Deep Learning Tutorial, http://deeplearning.stanford.edu/tutorial/supervised/ConvolutionalNeuralNetwork/, (07.07.2019)

[29] Koppula H. S., \& Saxena, A., (2015). Anticipating human activities using object affordances for reactive robotic response. IEEE transactions on pattern analysis and machine intelligence, 38, 14-29.

[30] Lu, Y., Yi, S., Zeng, N., Liu, Y., \& Zhang, Y., (2017). Identification of rice diseases using deep convolutional neural networks. Neurocomputing, 267, 378-384.

[31] Ali A., \& Hanbay, D., (2018). Bölgesel evrişimsel sinir ağları tabanlı MR görüntülerinde tümör tespiti. Gazi Üniversitesi Mühendislik-Mimarlık Fakültesi Dergisi, 2018.

[32] Özkan İ., \& Ülker, E., (2017). Derin Öğrenme ve Görüntü Analizinde Kullanılan Derin Öğrenme Modelleri. Gaziosmanpaşa Bilimsel Araştırma Dergisi, 6, 85-104.

[33] Ren, S., He, K., Girshick, R., \& Sun, J., (2015). Faster r-cnn: Towards real-time object detection with region proposal networks. Advances in neural information processing systems, 2015, 91-99.

[34] Rohith. G., (2018). R-CNN, Fast R-CNN, Faster R-CNN, YOLO-Object Detection Algorithms. https://towardsdatascience.com/r-cnn-fast-r-cnn-faster-r-cnn-yolo-object-detection-algorithms36d53571365e, (07.07.2019).

[35] LabelImage. https://github.com/tzutalin/labelImg, (13.07.2019). 